\title{
Total flavonoid contents and in silico study of flavonoid compounds from Meniran (Phyllanthus niruri L.) towards alpha-amylase and alpha-glucosidase enzyme
}

\author{
Sri Luliana*1, Rise Desnita ${ }^{1}$, Ronny Martien ${ }^{2}$, Arief Nurrochmad ${ }^{2}$ \\ ${ }^{I}$ Departement of Pharmacy, Faculty of Medicine Tanjungpura University Pontianak \\ Jl. Prof.Hadari Nawawi, Pontianak 78121, Indonesia \\ ${ }^{2}$ Faculty of Pharmacy Gajah Mada University Yogyakarta \\ Sekip Utara, Yogyakarta 55281, Indonesia
}

Accepted: 14-03-2019

\begin{abstract}
Meniran (Phyllanthus niruri L.) is a plant that is reported to contain flavonoids and shows the activity as a type 2 anti-diabetic by a mechanism of inhibiting the absorption of glucose. Flavonoid compounds such as rutin, quercetin and hesperidin shows anti-diabetic activity. This research aims to determine the levels of total flavonoids and docking studies of flavonoids from $P$. niruri against $\alpha$-amylase and $\alpha$-glucosidase. Analysis of total flavonoid content utilizes colorimetric method using $\mathrm{AlCl}_{3}$ and rutin standard, the docking study uses Autodock Vina program with the assistance of AutoDockTools (ADT) and visualization of docking results using Discovery Study. The results of the determination of total flavonoids level was $12.32 \pm 0.53$ $\mathrm{mgRE} / \mathrm{g}$ extract whereas in ethyl acetate and water fraction each were $19.33 \pm 0.68$ and $20.07 \pm 1.23$ $\mathrm{mgRE} / \mathrm{g}$, respectively. Results of all flavonoids docking study showed the potential to bind to both receptors, rutin has better binding energy towards $\alpha$-amylase whereas against $\alpha$-glucosidase is demonstrated by 3-O $-\beta$-D-glucopyranosyl-(2-1)- $O-\beta$-D-xylopyranoside quercetin.
\end{abstract}

Keywords: Phyllanthus niruri L., flavonoid, docking studies, $\alpha$-amylase, $\alpha$-glucosidase

*Corresponding author:

Sri Luliana

Departement of Pharmacy, Faculty of Medicine Tanjungpura University Pontianak

Jl. Prof.Hadari Nawawi, Pontianak 78121, Indonesia

Email: lulisri@gmail.com 


\section{INTRODUCTION}

Traditionally, many plants can be used as an anti-diabetic medication. One of the medicinal plant often used by the local community as an Original Indonesian Medicine (OIM) or by the international community is Phyllanthus niruri L. which is from Phyllanthaceae family. In vivo study of $P$. niruri leaves and fruits water extract at $150-600 \mathrm{mg} / \mathrm{kgbw} /$ day is effective in controlling insulin resistance in mice inducted with $10 \%$ of sucrose (Adeneye, 2012). The methanol extract of this herb is also capable of lowering blood sugar and body weight of rats which is induced using alloxan and could inhibit $\alpha$-amylase, and $\alpha$-glucosidase enzyme with $\mathrm{IC}_{50}$ of $2.15 \pm 0.1$ and $0.2 \pm 0.02 \mathrm{mg} / \mathrm{mL}$ (Okoli et al., 2011). Secondary metabolites in P. niruri were alkaloid, flavonoid, hydrolyzed tannin (ellagitanin), lignin, polyphenol, sterol and essential oil (Patel et al., 2011). Quercetin and rutin flavonoids in a dose of $100 \mathrm{mg} / \mathrm{kgbw}$ each significantly $(\mathrm{p}<0.05)$ lower blood sugar level in diabetic rats. Rutin and quercetin shows best antidiabetic activity each at the $2^{\text {nd }}$ and $4^{\text {th }}$ hour of administration. Rutin lowers blood sugar more compared to the positive control, glibenclamide (Jadhav and Puchchakayala, 2012). Quercetin and rutin is a flavonoid contained in $P$. niruri. Other than those two flavonoids, $P$. niruri also contains gallocathechin, nirurin, niruriflavone, quercetin, quercitrin, astragalin and 3-O- $\beta$-D-glucopyranosyl-(2-1)- $O-\beta$-Dxylopyranoside quercetin (Bagalkotkar et al., 2006).

Potential medicine from natural materials need to be developed, as most of conventional medicines are derived from plants. Medicinal compounds derived from natural materials can bind with one or more receptor (Siswandono, 2000). Interaction between the compound and receptor can be known using docking study. Docking studies has been proven to found the effectiveness of a compounds with receptors based on energy and the bonding type (Yanuar, 2012). Some of the compounds from plants are known to have the potency as type 2 anti-diabetic medication with the mechanism of inhibiting alpha amylase and glucosidase enzyme. Docking study results stated that compounds like curcumin, 16-hydroxychloride-3,13 dina-16,15-olide $(16 \mathrm{H})$, docosanol, tetracosanol, anto quinolol, berberine, catechin, quercetin, actinodafnine and rutin has the ability to bind to both alpha amylase and alpha glucosidase receptors (Jhong et al., 2015). Based on these research, flavonoids compound is potential to be an anti-diabetic agent. Research regarding the docking study of flavonoids and total flavonoid contents from $P$. niruri has never been done. This research aims to determine the total flavonoid content from extract and fraction of $P$. niruri and its flavonoid affinity against $\alpha$-amylase and $\alpha$-glucosidase receptor through docking studies.

\section{MATERIALS AND METHOD Equipment and Materials}

Laptop (Asus X455L with Intel Core i3 ${ }^{\mathrm{TM}}$ ), ChemDraw program (version 15.0) to create 2dimensional (2D) structure, ChemOffice 3D (version 15.0) to create a 3-dimensional structure (3D), a database of protein from the protein data bank and NCBI, Autodock Vina (Version 1.1.2) with the assistance of Auto Dock Tools (ADT) and visualization results of Docking by using Discovery Studio, UV-Vis Spectrophotometer (UV Thermo Scientific Genesys 10 UV Scanning), rotary evaporator (Rotavapor BUCHI II), analytical scale, UV 254 and $366 \mathrm{~nm}$ lamp, P. niruri powder, Quercetin (sigma Aldrich), $\mathrm{AlCl}_{3}$ (Merck), methanol p.a (Merck), n-hexane (Merck), ethyl acetate p.a. (Merck), working ethanol, $\mathrm{FeCl}_{3}, \mathrm{Mg}$ tape, $\mathrm{HCl}$ p.a. (Merck), $\mathrm{H}_{2} \mathrm{SO}_{4}$ p.a (Merck), Mayer reagent, Dragendorff reagent, Wagner reagent, glacial acetic acid (Merck), gelatin 1\%, $\mathrm{NaCl} 10 \%$, TLC (silica gel $\mathrm{GF}_{254}$ ), butanol p. a. (Merck), toluene p.a. (Merck), Sodium acetate (Merck) and aquadest.

Pharmaciana Vol. 9, No. 1, May 2019, Page. 1-10 


\section{Methods}

This research starts from the extraction of oil, and subsequently phytochemical screening and determination of total flavonoids from the extracts and fractions of $P$. niruri docking studies of the flavonoid compounds which structure known from literature study.

\section{Sample preparation, extraction and fractionation}

Dried $P$. niruri herb were sourced from the area of Yogyakarta, Indonesia through supplier and distributor of herbs/herbal (Herbal Anugrah Alam). Dried herbs were powdered and microscopically tested to ensure the species of the samples. Subsequently, maceration was done using $70 \%$ ethanol. Liquid extract obtained were collected into one and condensed using a rotary evaporator at a temperature of $50^{\circ} \mathrm{C}$ to obtain thick extract. Obtained thick extract were partitioned by liquid-liquid partition method using a separatory funnel. Thick extract was dissolved into warm aquadest, then n-hexane was added and shaken inside a separatory funnel. After shaking finishes, two layer of immiscible liquid will form, the water layer was separated from the n-hexane. This process is repeated until the $n$-hexane solvent became clear. The water layer was added with ethyl acetate and was fractionated repeatedly until the ethyl acetate layer became clear. n-Hexane, ethyl acetate and aqueous fraction was then condensed with vacuum oven up to obtain condensed fraction (Ahmad et al., 2018).

\section{Determination of total flavonoid content}

Analysis of total flavonoid content uses aluminum chloride $\left(\mathrm{AlCl}_{3}\right)$ colorimetric method. $\mathrm{An}$ aliquot of extract and fraction are inserted into a $25 \mathrm{~mL}$ measuring flask (concentration of 500$1000 \mu \mathrm{g} / \mathrm{mL}$ ) was diluted in methanol. About $2 \mathrm{~mL}$ of the sample was then added with $0.15 \mathrm{~mL}$ of $\mathrm{NaNO}_{2}$ and incubated for 6 minutes, $10 \% \mathrm{AlCl}_{3}$ was added into the sample and incubated for another 6 minutes, and $2 \mathrm{~mL}$ of $4 \% \mathrm{NaOH}$ were added after the incubation. After 15 minutes of incubation, the result of the reaction was ready to be measured in a UV-VIS Spectrophotometer at a wavelength of $511.5 \mathrm{~nm}$ (Surana et al., 2016).

\section{Docking study}

Docking study begins with the preparation of ligands i.e. creating a 2D structure of rutin, quercetin, gallocathechin, niruriflavone, nirurin, quercetol, quercitrin, astragalin, and 3-O - $\beta$-Dglucopyranosyl-(2-1)-O- $\beta$-D-xylopyranoside quercetin using ChemDraw Program (version 15.0). Each of the structure above were then made into 3D structure using ChemOffice 3D (version 15.0) which can observe the stereochemistry $3 \mathrm{D}$ form and set up the most stable form of the compounds by minimalizing the energy using MM2 Minimize energy tools in the program, to obtain the most compatible form in binding the stereochemistry receptor (Liu-Qiong Hou et al., 2015). Detection of active site, and analysis of bind amino acid receptor was done using Autodock Vina (version 1.1.2) with the assistance of AutoDockTools (ADT) was done to all detected potential active site (cavity) within alpha-amylase and alpha-glucosidase receptor. Energy is rated based from binding energy (kcal/mol) and RMSD (Root Mean Square Deviation). In addition, the possibility of hydrogen bonds between donor and acceptor (receptor ligands) were also observed. Parameters which were commonly used to observe the drug-receptor bond was binding energy, while visualization of docking results was done using Discovery Studio, and then the data was analyzed (Jhong et al., 2015).

\section{RESULTS AND DISCUSSION Extraction and fractionation}

Extraction of 1,128.5 g of powdered sample resulted in $284.14 \mathrm{~g}$ of thick extract with yield of $25.17 \%$. The extraction was done by maceration, by soaking the powdered sample using solvents inside a maceration vessel. Maceration was chosen because it is safe for compounds that 
are not resistant to high temperatures, furthermore the method is simple and uses basic instruments. The use of powdered sample aims to expand the surface on which the sample will be extracted, allowing for the extraction of more chemical components from the sample. Ethanol $70 \%$ is used as a solvent due to its nature as a polar solvent, which would optimize the extraction by extracting a number of chemical components that are either polar or nonpolar. In accordance with the laws of solubility: "like dissolves like", which means that solubility will occurs when both solvent and solute has the same polarity, which can dissolve metabolite-secondary metabolite in plants (Harborne, 1987).

Fractionation or partition, also called liquid-liquid extraction is a process of separating a substance in 2 immiscible liquids or in other words, a comparison of the concentration of a substance dissolved in organic and water solvent. The result of fractionation in each solvent produces different amount of fraction, this is possible because of the nature of the substance which can be dissolved into water and there are substances that can be dissolved in an organic solvent (Rydberg, 2004), there is also a difference in the level of solubility of each solvent used. In this research, fractionation is done gradually from non-polar solvent to polar solvent, in order to separate a substance based on its solubility (Simon Gibbons and Alexander, 2006). n-Hexane, ethyl acetate and aqueous fraction which is obtained from $168.94 \mathrm{~g}$ of ethanol extracts were $5.63 ; 10.47$ and $51.40 \mathrm{~g}$, with yield of $3.33 ; 6.20$ and $30.43 \%$, respectively. Then the chemical content extracts and fractions were identified through phytochemical screening.

\section{Phytochemical screening of extract and fraction}

The extract which is obtained in the form of ethanol extracts with dark green color and has specific odor. Phytochemical screening of ethanol extracts and fractions of $P$. niruri showed the ethanol extracts, ethyl acetate fractions and aqueous fractions contain flavonoid but $n$-hexan fractions not yet. Phytochemical screening of the extracts and fractions of P. niruri as listed in Table I.

Table I. Phytochemical screening results

\begin{tabular}{lcccccc}
\hline Plant Sample of & \multicolumn{7}{c}{ Class of Compound } \\
\cline { 2 - 7 } $\boldsymbol{P}$. niruri L. & Phenol & Flavonoid & Tannin & Steroid & Alkaloid & Saponins \\
\hline Ethanol Extract & + & + & + & + & + & + \\
n-hexane Fraction & + & - & + & + & - & - \\
Ethyl Acetate Fraction & + & + & + & + & + & - \\
Aqueous Fraction & + & + & + & - & - & - \\
\hline
\end{tabular}

\section{The result of total flavonoid content analysis}

Based on the results of phytochemical screening, flavonoids were identified in the sample ethanol extracts, ethyl acetate fractions and aqueous fractions. The determination of total flavonoid content in the sample ethanol extracts, ethyl acetate fractions and aqueous fraction are then conducted. Determination of total flavonoid content with $\mathrm{AlCl}_{3}$ colorimetric method uses rutin as the base standard. The determination of maximum wavelength resulted in $511.5 \mathrm{~nm}$. A standard curve is made to calculate total flavonoid content in the extracts and fractions of $P$. niruri. The result of total flavonoid content determination is $12.32 \pm 0.53 \mathrm{mgRE} / \mathrm{g}$ extracts while the result for ethyl acetate and aqueous fractions were $19.33 \pm 0.68$ and $20.07 \pm 1.23 \mathrm{mgRE} / \mathrm{g}$ 
respectively. Flavonoids have the ability to ward off free radicals and binds to metal, this gives relationship hypotheses between diabetes and the inflammation, as well as the potency of flavonoids to protect the body from free radicals and other pro oxidative compounds. The consumption of flavonoid-rich foods or flavonoids can reduce the risk of diabetes (Vinayagam \& $\mathrm{Xu}, 2015)$. Some flavonoids from various plants have been tested in-vitro as well as in-vivo with various methods, which indicates anti-diabetic activity like quercetin, hesperidin, caempherol, apigenin, luteolin, naringenin, isorhamnetin and rutin (Vinayagam \& Xu, 2015).

\section{Docking Study Result}

Docking method used in this study is AutoDock Vina with the assistance of AutoDockTool (ADT). Study of docking is done by comparing the drug compounds which activity is biologically proven to the target receptors of the drug. This research uses Acarbose as the comparison substance. Medicinal compound, hereinafter referred to as ligand is analyzed for its physicochemical properties using ChemOffice. The structure of quercetin, rutin, gallocathechin, niruriflavone, nirurin, quercetol, quercitrin, astragalin, and 3- $O-\beta$-D-glucopyranosyl-(2-1)- $O-\beta$-Dxylopyranoside quercetin are drawn in two dimensions (2D).

Table II. The result of ligands physicochemical properties determination

\begin{tabular}{lll}
\hline Compound Name & Log P & MW \\
\hline Rutin & -2.28 & 610.15 \\
Quercetin & 0.35 & 302.04 \\
Gallocathechin & 1.11 & 306.07 \\
Niruriflavone & 1.33 & 364.03 \\
Nirurin & 0.96 & 516.16 \\
Quercetol & 2.74 & 354.15 \\
Quercitrin & -0.54 & 448.10 \\
Astragalin & -1.2 & 432.11 \\
3- $O$ - $\beta$-D-glucopyranosyl-(2-1)- $O-\beta$-D-xylopyranoside quercetin & 997.13 & 626.15 \\
Acarbose (Positive Control) & -6.8 & 645.60 \\
\hline
\end{tabular}

The results of the physicochemical analysis based on the structure, molecular weight, $\log \mathrm{P}$ values as listed in Table II. It can be seen that most of the molecular weight is $<500$, but rutin, nirurin and 3-O- $\beta$-D-glucopyranosyl-(2-1)- $O-\beta$-D- xylopyranoside quercetin were $>500$. The average $\log \mathrm{P}$ values is $<5$, but it was $>5$ in $3-O-\beta$-D-glucopyranosyl-(2-1)- $O-\beta$-Dxylopyranoside quercetin. The number of $\mathrm{H}$ donor $(\mathrm{OH}$ and $\mathrm{NH}$ cluster) is $>5$. Based on the Lipinski's rule of five, $<5$ means it has excellent permeability. Compounds with MW $<500 \mathrm{~g} / \mathrm{mol}$ can easily penetrate biological membranes. The value of $\log \mathrm{P}$ describes the ability of a compound to dissolve in biological membrane liquid. The optimum value for $\log \mathrm{P}$ based on Lipinski's rule of five is $<5$. Based on the data analysis, flavonoids are easily absorbed and have excellent permeability, except for 3-O- $\beta$-D-glucopyranosyl-(2-1)- $O-\beta$-D-xylopyranoside quercetin (Block, $2011)$. The $2 \mathrm{D}$ structure compounds are drawn in $3 \mathrm{D}$ form using Chem Office 3D. Compounds that bind to the receptor should be drawn in 3D as pdb format. This is due to the compound that will be docked can only be visualized in the form of 3D formats such as pdb by Autodock Vina. Pdb format files have the required data for the docking purposes, such as atom positions, coordinates of molecules and chains of amino acids of a macromolecule (Yanuar, 2012). 
Table III. The result of molecular docking towards $\alpha$-amylase and $\alpha$-glucosidase receptor

\begin{tabular}{lcc}
\hline \multicolumn{1}{c}{ Compound Name } & $\begin{array}{c}\text { Docking Score } \\
\text { towards } \\
\boldsymbol{\alpha} \text {-Amylase }\end{array}$ & $\begin{array}{c}\text { Docking Score } \\
\text { towards } \\
\text { a-Glucosidase }\end{array}$ \\
\hline Rutin & -9.6 & -6.8 \\
Quercetin & -8.5 & -6.4 \\
Gallocathechin & -8.5 & -6.0 \\
Niruriflavone & -8.3 & -6.1 \\
Nirurin & -9.4 & -6.7 \\
Quercetol & -8.9 & -6.7 \\
Quercitrin & -8.8 & -6.8 \\
Astragalin & -9.1 & -6.7 \\
3-O- $\beta$-D-glucopyranosyl-(2-1)- $O-\beta$-D- & -8.9 & -7.5 \\
xylopyranoside quercetin & & -7.2 \\
Acarbose (Positive Control) & -8.1 & \\
\hline
\end{tabular}

The data in Table III shows that the binding energy of $P$. niruri flavonoid compounds towards receptor $\alpha$-amylase is lower than acarbose. It can illustrate that flavonoids from $P$. niruri are potentially forming a bond with $\alpha$-amylase. The binding energy of $P$. niruri flavonoid compounds towards $\alpha$-receptor glucosidase is greater than acarbose but the binding energy of 3-O$\beta$-D-glucopyranosyl-(2-1)- $O-\beta$-D-xylopyranoside quercetin is lower. Overall, these compounds have the potential to bind to $\alpha$-amylase or $\alpha$-glucosidase receptor. This is in accordance with the theory of energy enthalpy, where the lower binding energy is (exothermic) between a compound with a receptor (product) compared to compound itself, then it is easier to form a bond between compounds with receptor (Chan, 2010; Trott \& Olson, 2010). Based on the data above, the next selected compounds with the highest docking score (binding energy) be visualized as a result of docking. In this research, rutin is further visualized towards $\alpha$-amylase while $3-O-\beta$-Dglucopyranosyl-(2-1)- $O-\beta$-D-xylopyranoside quercetin is visualized towards $\alpha$ glucosidase using Autodock Vina version 1.1.2 with the assistance of AutoDockTools and visualization of the docking result using Discovery Studio.

The molecular stuctures of rutin by high docking scores on $\alpha$-amylase as shown in Figure 1 and the 3-O- $\beta$-D-glucopyranosyl-(2-1)- $O-\beta$-D-xylopyranoside quercetin on $\alpha$-glucosidase inhibitors detected in virtual screening were shown in Figure 3. Rutin ligan (in rutin- $\alpha$-amylase complex) perform hydrogen bonding with amino acid residues Gln A:63 and Glu A:233 and has $\pi-\pi$ interaction with amino acid residues Trp A:59 and Thr A:163 while acabose as positive control only perform hydrogen bonding with amino acid residues Asp A:197, Glu A:233, Asn A:105, Gln A:63 and Thr A:163 as shown in Figure 2. The 3- $O-\beta$-D-glucopyranosyl-(2-1)- $O-\beta$-Dxylopyranoside quercetin- $\alpha$-glucosidase complex shown the amino acid residues that participated in hydrogen bonding were Arg A:655, Glu A:765 and Phe A:727. This compound also has $\pi-\pi$ interaction with amino acid residues Thr A:648. Hydrogen binding also performed between acarbose with $\alpha$-glucosidase inhibitors. The amino acid residues are Gln A:655, Tyr A:729, Leu A:726 and Glu A:765 as shown in Figure 4. Some of the research in-vitro shown the flavonoids have shown promising inhibition of $\alpha$-amylase and $\alpha$-glucosidase (Kim et al., 2010; Pereira et al., 2011). Flavonoid it was possible to observe that the flavone with a $-\mathrm{C}_{1}$ ion at 3-position of $\mathrm{C}$-ring, an - $\mathrm{OH}$ group at 3'- and 4'- positions of B-ring and at 5- and 7-positions of A-ring and the $\mathrm{C}_{2}=\mathrm{C}_{3}$ double bond, was the most active tested flavonoid, through competitive inhibition (Proenca, et al., 2019).

Pharmaciana Vol. 9, No. 1, May 2019, Page. 1-10 

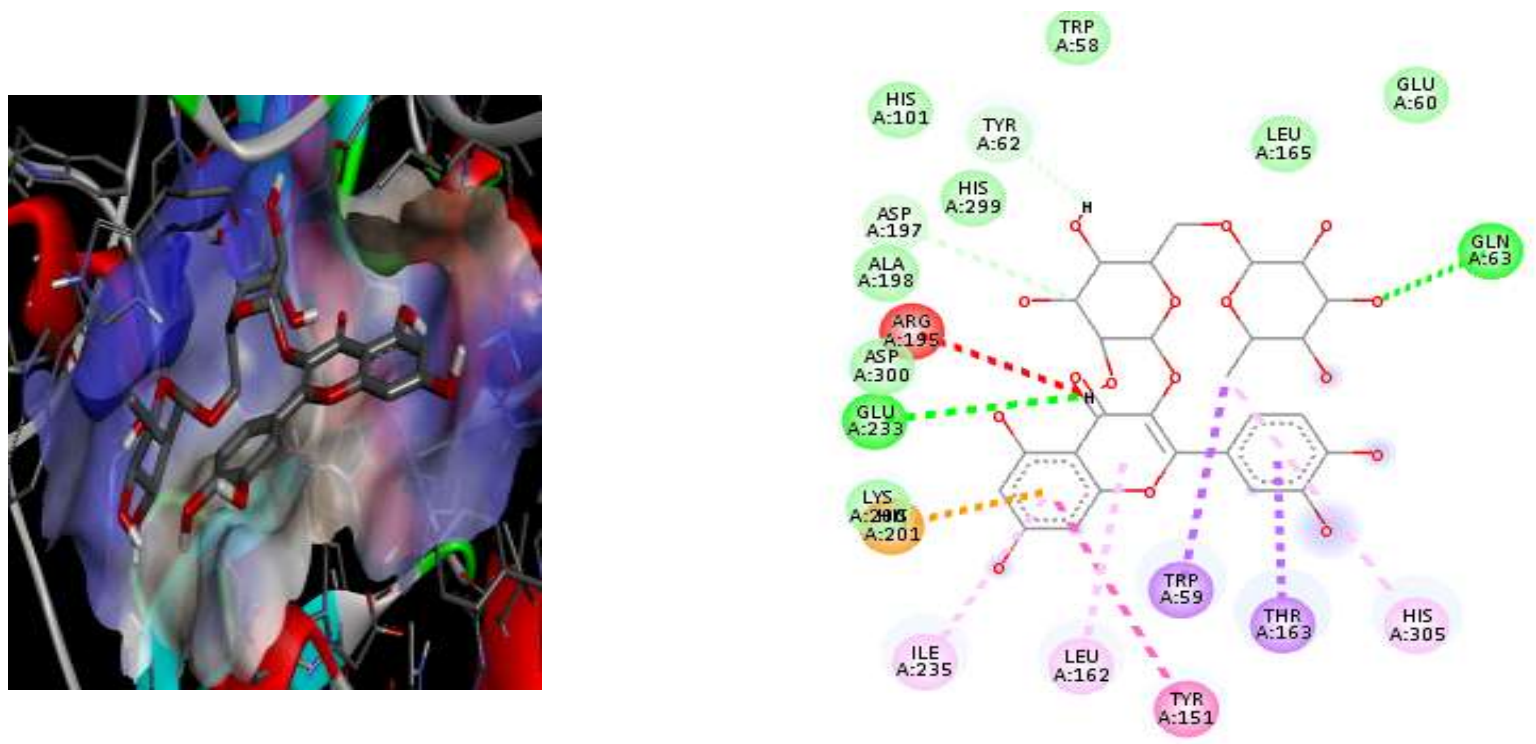

Interactions

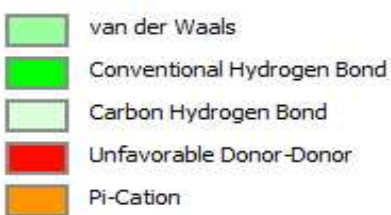

Pi-Donor Hydrogen Bond

Pi-Sigma

Pi-Pi Stacked

Pi-Alkyl

Figure 1. Interaction hydrophobic visualization and interaction 2D rutin with $\alpha$-amylase receptors
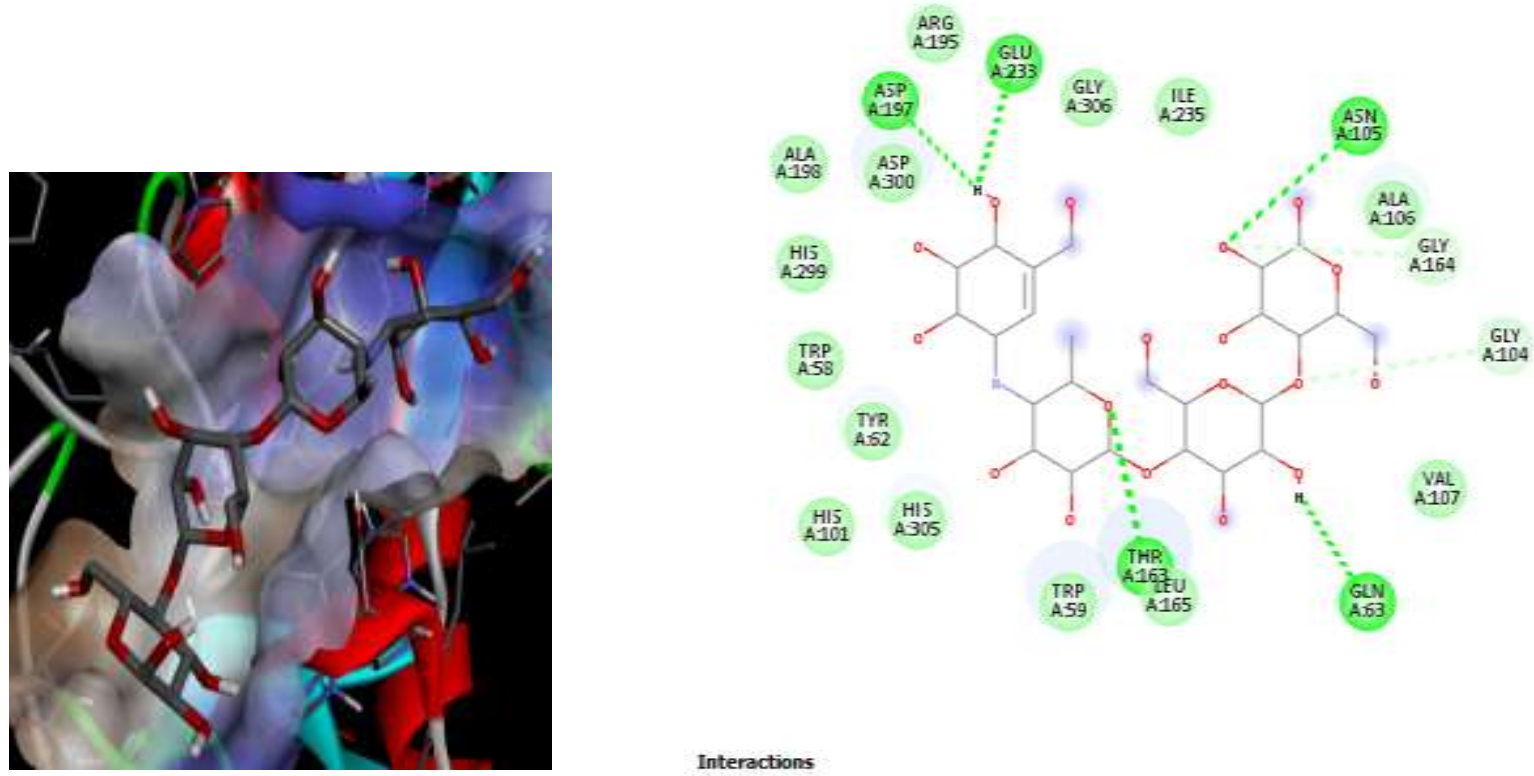

Interaction

van der Waals

Conventional Hydrogen Bond

Carbon Hydrogen Ban

Figure 2. Interaction hydrophobic visualization and interaction 2D acarbose with $\alpha$-amylase receptors 

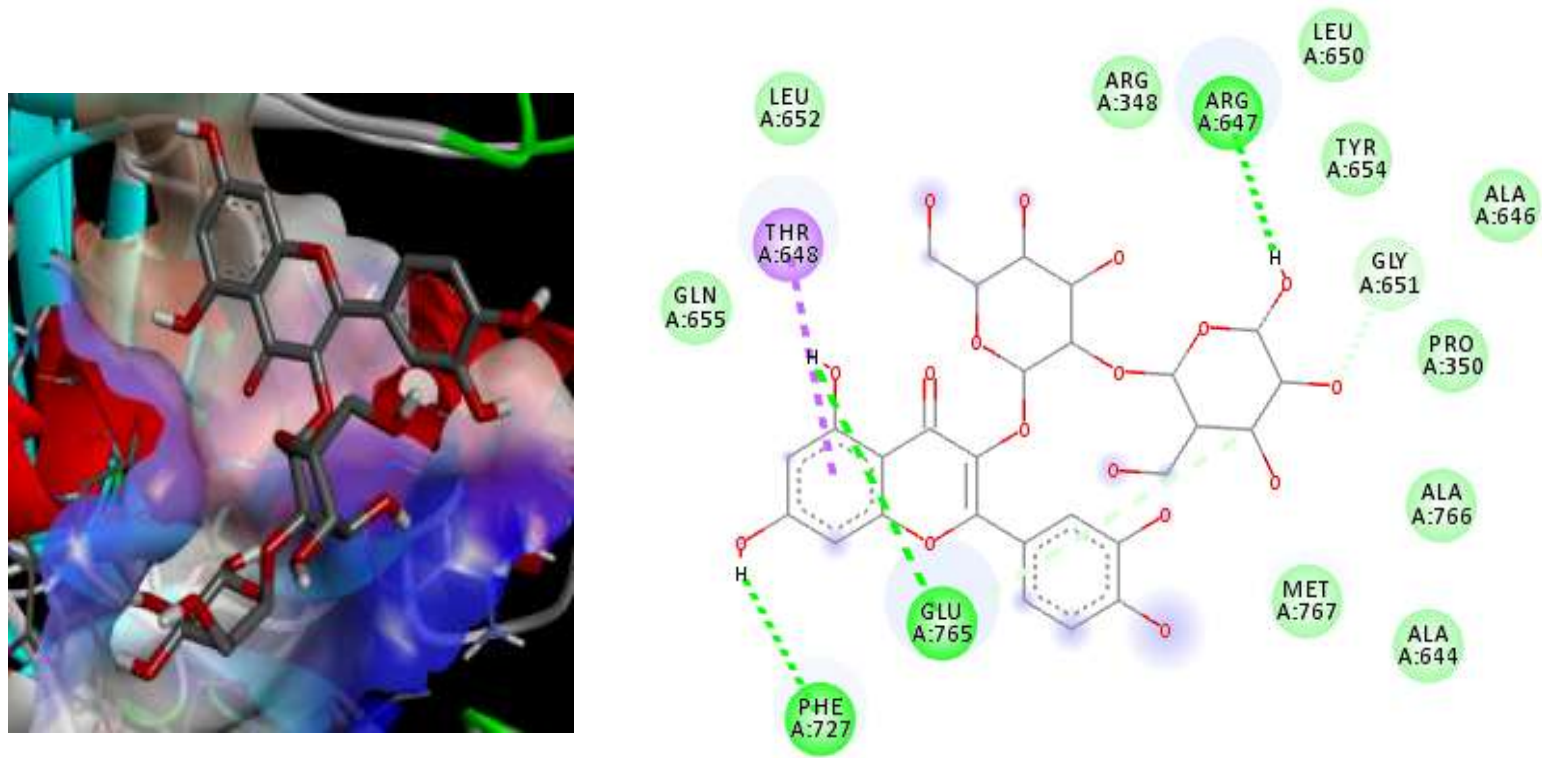

Interactions

$\begin{array}{ll}\square \text { van der Waals } & \text { Carbon Hydrogen Bond } \\ \text { Conventional Hydrogen Bond } & \text { Pi-Sigma }\end{array}$

Figure 3. Interaction hydrophobic visualization and interaction 2D quercetin 3-O- $\beta$-Dglucopyranosyl-(2-1)-O- $\beta$-D-xylopyranoside with $\alpha$-glucosidase receptors

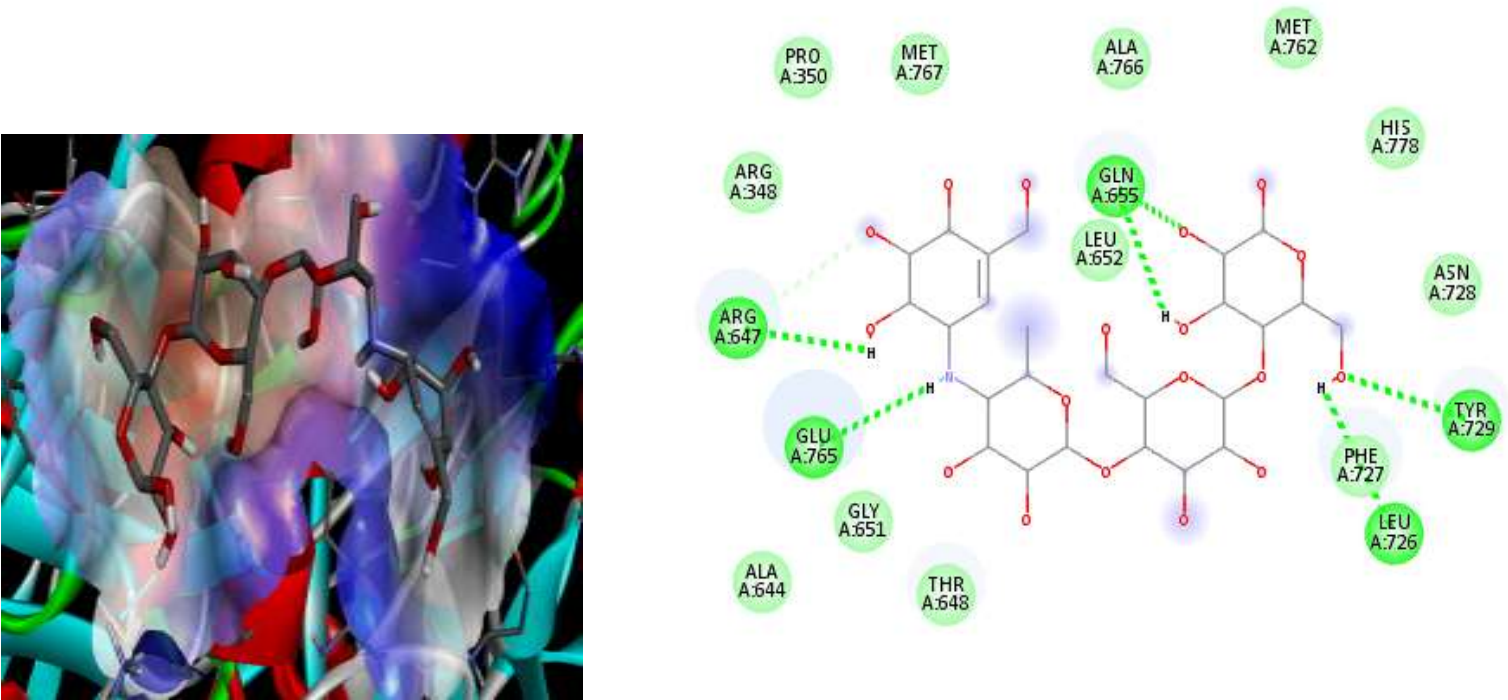

Interactions

van der Waals

Conventional Hydrogen Bond

Carbon Hydrogen Bond

Figure 4. Interaction hydrophobic visualization and interaction 2D acarbose with $\alpha$ glucosidase receptors

Pharmaciana Vol. 9, No. 1, May 2019, Page. 1- 10 


\section{CONCLUSION}

Total flavonoid content is higher in fraction than in extract. Flavonoid compounds of $P$. niruri potentially inhibit $\alpha$-amylase and $\alpha$-glucosidase, rutin showed better activity than acarbose towards $\alpha$-amylase and 3-O- $\beta$-D-glucopyranosyl-(2-1)- $O-\beta$-D-xylopyranoside quercetin is better than acarbose towards the $\alpha$-glucosidase. Results of all flavonoids docking study showed the potential to bind to both receptors, rutin has better binding energy towards $\alpha$-amylase whereas against $\alpha$-glucosidase is demonstrated by $3-O-\beta$-D-glucopyranosyl-(2-1)- $O-\beta$-D-xylopyranoside quercetin.

\section{REFERENCES}

Adeneye, A.A., 2012, The leaf and seed aqueous extract of Phyllanthus amarus improves insulin resistance diabetes in experimental animal studies, Journal of Ethnopharmacology, 144(3): $7-11$.

Ahmad, I., A. Mun'im, S. luliana, B. Elya, Azminah, A. Yanuar, Y. Artha and O. Negishi, 2018, Isolation, elucidation, and molecular docking studies of active compounds from Phyllanthus niruri with angiotensin-converting enzyme inhibition. Pharmacognosy Magazine, 14: 604610.

Bagalkotkar, G., S.R. Sagineedu, M.S. Saad and J. Stansias, 2006, Phytochemicals from Phyllanthus niruri Linn. and their pharmacological properties: A review, The Journal of pharmacy and pharmacology, 58: 1559-1570.

Block, J.H., 2011, Drug design strategies, In: Beale JM, Block JH. Eds. Wilson and Gisvold's textbook of organic medicinal and pharmaceutical chemistry, $12^{\text {th }}$ Ed. Philadelphia: Lippincott Williams and Wilkins, 38-49.

Chan S.L, Labute P., 2010, Training a scoring function for the alignment of small molecules. Journal Chemistry Information Model, 50:1724-1735.

Harbone, J.B., 1987, Metode Fitokimia: Penuntun cara modern menganalisis tumbuhan, Penerjemah Kosasih Padmawinata dan Iwang Soediro, Bandung: ITB Press.

Hou, L., Y. Liu, Y. Zhang, 2015, Garlic intake lowers fasting blood glucose: meta-analysis of randomized controlled trials. Asia Pacific journal of clinical nutrition, 24 (4): 576-582.

Jadhav, R. \& Puchchakayala, G., 2012, Hipoglycemic and antidiabetic activity of flavonoids: boswllic acid, ellagic acid, quercetin, rutin on streptozotocin-nicotinamide induced type 2 diabetic rats. International Journal of Pharmacy and Pharmaceutical Sciences, 4(2): 2-7.

Jhong, C.H., J. Riyaphan, S. Lin, Y. Chia, and C. Weng, 2015, Screening alpha-glucosidase and alpha-amylase inhibitors from natural compounds by molecular docking in silico, BioFactors, 41 (4): 242-251.

Kim, H., Jin-Kwang Kim, L. Kang, K. Jeong, and S. Jung, 2010, Docking and scoring of quercetin and quercetin glycosides against $\alpha$-amylase receptor. Bull. Korean Chem. Soc. 2010, 31, 461-463.

Patel, J.R., P. Tripathi, V. Sharma, N.S. Chauhan, and V.K. Dixitet, 2011, Phyllanthus amarus: ethnomedicinal uses, phytochemistry and pharmacology: a review, Journal of ethnopharmacology, 138 (2): 286-313.

Pereira, D.F., L.M. Cazarolli, C. Lavado, V. Mengatto, M.S.R.B. Figueiredo, A. Guedes, M.G. Pizzalatti, F. Regina and M.B. Silva, 2011, Effects of flavonoids on $\alpha$-glucosidase activity : potential targets for glucose homeostasis, Nutrition, 27: 1161-1167.

Proenca, C., M. Freitas, D. Ribeiro, S.M. Tome, E. F.T. Oliveira, M.F. Viegas, A.N. Araujo, M.J. Ramos, A.M.S. Siva, P.A. Fernandes and E. Fernandes, 2019, Evaluation of a flavonoids library for inhibition of pancreatic a-amylase towards a structure-activity relationship, Journal of Enzyme Inhibition and Medicinal Chemistry, 34 (1): 577-588.

Okoli, C.O., I.C. Obidike, A.C. Ezike, P.A. Akah, O.A.Salawu, 2011, Studies on the possible mechanisms of antidiabetic activity of extract of aerial parts of Phyllanthus niruri. Journal of pharmakology, 49 (3): 248-255. 
Rydberg, J., M. Cox, C. Musikas and G.R. Chappin, 2004, Solvent extraction principles and practice 2nd ed., New York: M. Dekker.

Simon Gibbons and Alexander I. G., 2006, Natural products isolation $2^{\text {nd }}$ ed. R. J.P.Cannell, ed., New Jersey.

Siswandono, B., 2000, Kimia Medisinal 1, Surabaya: Airlangga University press.

Surana, A.R., Manoj R.K., and Rajendra D.W., 2016, Estimation of total phenolic and total flavonoid content and assessment of in vitro antioxidant activity of extracts of Hamelia patens Jaq. Stems, Research Journal of Phytochemistry, 10 (2): 67-74.

Trott, O. \& A.J. Olson, 2010, AutoDock Vina: Improving the speed and a ccuracy of docking with a new scoring function, efficient optimization and multithreading, Journal Comp Chem, 31: $455-461$.

Vinayagam, R. \& Xu, B., 2015, Antidiabetic properties of dietary flavonoids: A cellular mechanism review, Nutrition \& Metabolism, 1-20.

Yanuar, A., 2012, Penambatan Molekuler. Praktek dan Aplikasi pada Virtual Scrining, Depok: Fakultas Farmasi Universitas Indonesia. 